\title{
ELEMENTOS DA BASE DE CONHECIMENTOS \\ PARA O ENSINO: UMA ANÁLISE DE \\ LICENCIANDOS EM FÍSICA EM \\ DESENVOLVIMENTO DE ATIVIDADES \\ PEDAGÓGICAS
}

\author{
Elementos de base de conocimientos para la enseñanza: un \\ análisis de los estudiantes de pregrado de enseñanza de la \\ Física desarrollando actividades pegagógicas
}

\section{Teaching knowledge bases elements: an analysis of undergraduate physics teachers in pedagogical activities development}

\section{Leonardo dos Santos Cunha}

ORCID: https://orcid.org/0000-0002-1884-2746

Universidade Federal de Itajubá (UNIFEI)

leonardodosscunha@yahoo.com.br

\section{Luciano Fernandes Silva}

ORCID: https://orcid.org/0000-0003-2041-3809

Universidade Federal de Itajubá (UNIFEI)

lufesilv@gmail.com

\section{Agenor Pina da Silva}

ORCID: https://orcid.org/0000-0002-1445-1027

Universidade Federal de Itajubá (UNIFEI)

agenor@unifei.edu.br

\section{João Ricardo Neves da Silva}

ORCID: https://orcid.org/0000-0003-1311-0199

Universidade Federal de Itajubá (UNIFEI)

jricardo.fisica@unifei.edu.br

\section{Resumo}

O presente artigo visa analisar o conjunto dos conhecimentos manifestados por licenciandos em física participantes de um processo de planejamento conjunto de uma atividade didática de ensino de física em parceria com uma professora da educação básica. A partir da compreensão de que a formação de grupos de trabalho entre professores e licenciandos se configura como prática formativa, foram analisados os registros de falas entre esses membros de um grupo de planejamento conjunto dedicado a elaborar uma atividade didática voltada ao ensino de mecânica. As transcrições dos encontros foram caracterizadas com base no marco teórico da Base de Conhecimentos para o Ensino (BCE), especificamente dos Conhecimentos Pedagógicos de Conteúdo, a partir de Shulman (1986, 
1987,2004) e seus interpretadores para ao ensino de Física. Com os resultados, foi possível detectar os conhecimentos da BCE que são expressos pelos licenciandos no processo de planejamento conjunto com a professora e, então, refletir sobre a prática formativa implementada como forma de expressão desses conhecimentos. Isso permitiu relacionar a manifestação desses conhecimentos à participação em um processo formativo de grupos de planejamento conjunto.

Palavras-chave: Formação Inicial, Conhecimentos, Grupos de Trabalho, Educação Científica

\title{
Resumen
}

Este artículo tiene como objetivo analizar el conjunto de los conocimientos expresados por estudiantes de pregrado em física que participan em um proceso de planificación conjunta para una actividad didáctica de enseñanza de física em colaboración com un maestro de la escuela secundaria. Partiendo de la comprensión de que la formación de grupos de trabajo entre docentes y estudiantes de pregrado se configura como una estrategia de capacitación, fueron analizados los registros de discurso entre estos miembros de un grupo de planificación conjunta dedicado al desarrollo de una actividad didáctica dirigida a la enseñanza de la mecánica. Las transcripciones de los encuentros se caracterizaron en base en el marco teórico de la Base de Conocimientos para la Enseñanza (BCE), en específico el Conocimiento Didactico del Contenido, com base em los trabajos de Shulman $(1986,1987,2004)$ y sus interpretadores para la enseñanza de la Física. Como resultados, es posible detectar los conocimientos de la BCE que fueran expresados por los estudiantes de pregrado en el proceso de planificación en conjunto con la maestra, y así, reflexionar acerca de las prácticas de formación y su inflencia en la manifestación de estos conocimientos. Esto permite relacionar la manifestación de este conocimiento com la participación en um proceso de capacitación de grupos de planificación conjunta.

Palabras-clave: Formación inicial, Conocimientos, Grupos de trabajo, Educación Científica

\begin{abstract}
This article aims to analyze the set of knowledge expressed by physics graduates participating in a joint planning process of a didactic physics teaching activity in partnership with a teacher of basic education. From the understanding that the formation of working groups between teachers and graduates is configured as a formative strategy, we analyzed the speech records among these members of a joint planning group dedicated to elaborate a didactic activity focused on the teaching of mechanics. The transcripts of the meetings were characterized based on the references that address the teachers' knowledge, specifically the Pedagogical Content Knowledge based on Shulman (1986, 1987, 2004) and it's interpreters for physics teaching. It is possible to perceive a procedural construction of the pedagogical content knowledge, which allows to relate the manifestation of this knowledge to the participation in a formative process of joint planning groups.
\end{abstract}

Keywords: Inicial Formation, knowledges, Work groups, Scientific education

\section{Base de Conhecimento para o Ensino: fundamentos para análises de processos formativos de professores}

Ao se promover uma reflexão sobre as mudanças que vêm sofrendo os cursos de formação de professores de Física no Brasil, entende-se que as mais recentes propostas orientadoras desses cursos de cursos de licenciatura têm se preocupado em desenvolver uma formação mais próxima da prática e mais adequada às realidades da sala de aula (Dourado, 2015). Fundamentalmente, as mais recentes diretrizes curriculares para a formação de profissionais para o magistério da educação básica (Brasil, 2015) apresentam uma série de argumentos que se referem à necessidade de articulação entre a formação inicial e a formação continuada de professores, enfatizando a participação coletiva e colegiada tanto na discussão quanto na criação de estratégias formativas em processos de ensino. O documento ainda explicita que:

$\S 2^{\circ}$ A instituição formadora, em efetiva articulação com o planejamento estratégico do Fórum Estadual Permanente de Apoio à Formação Docente e 
com os sistemas e redes de ensino e com as instituições de educação básica, definirá no seu projeto institucional as formas de desenvolvimento da formação continuada dos profissionais do magistério da educação básica, articulando-as às políticas de valorização a serem efetivadas pelos sistemas de ensino (Brasil, 2015, p. 14)

Dessa maneira, a formação de professores em nível de licenciatura ${ }^{1}$ no Brasil está organizada a partir da ideia de que os cursos de licenciatura são cursos de formação específica e que desenvolvem conhecimentos específicos da docência, que no contexto deste trabalho nos reportamos aos de formação de professores em Física. Desse modo, a formação de professores no Brasil é realizada em cursos de formação que são independentes dos cursos de Física pura - que no Brasil são chamados de bacharelados. As principais características na formação dos licenciandos está a presença das Práticas como Componente Curricular (PCC) e dos Estágios Supervisionados, ambos com 400 horas de duração ao longo do curso. As PCC estão direcionadas para a formação do licenciando para as práticas de ensino específicas, ou seja, neste caso, se configuram como as práticas relacionadas ao ensino e que são desenvolvidas ao longo de todas as disciplinas do curso. Já os estágios supervisionados são obrigatórios em todos os cursos de licenciatura e são desenvolvidos nas escolas de educação básica, sob supervisão dos professores da escola.

Sendo assim, é possível colocar, em poucos termos, que a formação inicial de professores de Física no Brasil é desenvolvida em cursos de licenciatura, que são, grosso modo, compostos pelos seguintes conjuntos de disciplinas: 1.) Disciplinas de conteúdo específico de física; 2.) Disciplinas de conteúdo pedagógico e legislações educacionais brasileiras; 3.) Práticas como Componente Curricular; 4.) Estágios Supervisionados; e 5) Trabalho final de graduação.

Importante destacar ainda que a inserção das Práticas como Componente Curricular no currículo da formação inicial (Pereira, 2019) tem contribuído de forma significativa para a construção de processos de articulação entre os cursos de licenciatura e as escolas de educação básica. Neste contexto, podemos afirmar que há várias ações voltadas para a construção de articulações formativas mais efetivas entre a universidade e a escola de educação básica. A efetivação dessas ações vem acompanhada de muitas críticas direcionadas aos cursos de formação docente. Dentre essas críticas destacamos as considerações de Barcelos e Villani (2006), segundo os quais pode ser constatado nos cursos de licenciatura brasileiros que:

De um lado, a pouca articulação entre as várias atividades que constituem o currículo de formação dos licenciandos na universidade parece minar a possibilidade de visibilidade das propostas teóricas apresentadas. De outro lado, a falta de projetos que fortaleçam os vínculos entre a Educação Superior nas instituições formadoras de professores e as instituições de Educação Básica, para que haja trocas entre a universidade e a escola, parece tornar a formação inicial muito teórica e pouco realista (Barcelos\&Villani, 2006, p. 74).

1 No Brasil, "licenciado" é o nome utilizado para designar o profissional formado em um curso de licenciatura em física, que realizou um processo formativo para se tornar professor de física. Já o termo "bacharel", designa aqueles que se formam nos cursos de bacharelado em física, voltados para a formação puramente em física. 
Ou seja, apesar de haver nas diretrizes que organizam os cursos de licenciatura a clara menção à necessidade de que os professores em formação sejam colocados em contato direto com a escola de educação básica, ainda são muito superficiais as formas de estabelecimento dessa interação, que muitas vezes fica concentrada apenas na realização dos estágios na escola. Há a necessidade de estabelecimento de práticas de formação de professores de física que sejam construídas em interação direta e parceria com os professores da Educação Básica. Trabalhos tais como os de Bortoletto (2013), Orquiza de Carvalho (2005), Terneiro-Vieira (2016), entre outros, expõem uma série de argumentos que explicitam as potencialidades da congregação entre professores que já atuam em escolas e professores em processo de formação inicial, de modo a constituir espaços de formação em conjunto.

Não se trata, então, de haver ou não espaços oficiais de articulação entre a formação inicial e a escola de educação básica, mas do estabelecimento de estratégias que visem aprofundar práticas formativas que podem ser desenvolvidas nestes espaços e quais suas contribuições. A partir deste contexto, pesquisadores e profissionais da educação que atuam em cursos de licenciatura verificaram a necessidade de elaborar trabalhos investigativos que pudessem analisar o contato dos professores da educação básica e licenciandos. Consideramos em especial aquelas situações que possam envolver estudos e discussões voltadas para metodologias e conteúdos disciplinares específicos.

No que se refere especialmente às licenciaturas voltadas para as ciências da natureza, como a Física, a discussão muitas vezes se restringe aos aspectos relativos ao conflito conteúdo versus metodologias, uma vez que ambas são partes fundamentais da formação do futuro professor. Questões como "o licenciando deve aprender mais conteúdo específico ou mais conteúdo pedagógico?” são muito comuns no que se refere às propostas de formação de professores de física.

Diante da necessidade de buscar cada vez mais a articulação entre conteúdos específicos e conteúdos pedagógicos, argumenta-se então sobre a pertinência de que esta articulação provenha de práticas de formação de professores que se baseiem na construção conjunta de conhecimentos entre licenciandos e professores que atuam na educação básica. Nesse contexto, um fundamento deste estudo está relacionado com a análise do processo de construção de conhecimentos por licenciandos quando em uma situação de planejamento e criação de atividades pedagógicas em parceria com esses professores que atuam na Educação Básica.

Para realizar a análise de uma prática de planejamento conjunto e seus efeitos nos conhecimentos manifestados pelos licenciandos, nos embasamos em um referencial consagrado e bastante difundido na área de ensino de física, a saber, a Base de Conhecimentos para o Ensino (BCE), oriunda dos trabalhos pioneiros de Shulman (1986, 1987, 2004)

De acordo com Goes (2014), a formação do professor é objeto de estudo de diversas pesquisas, e nessas se discutem sobre quais seriam os conhecimentos necessários que um professor deve desenvolver para que sua atuação seja profissionalizada para o ensino de determinado conteúdo. $\mathrm{Na}$ discussão deste tema, é possível encontrar na literatura diversos modelos de formação e estratégias de articulação entre conteúdos e conhecimentos, todos voltados à caracterização das necessidades formativas de professores. Dentre esses modelos está o da BCE, que se trata da constituição de um conjunto de conhecimentos indispensáveis e caracterizadores da docência em conteúdo específico e que são constituídos tendo como fonte principal de reflexão o ensino de conteúdos. Na perspectiva de Shulman (2015), 
A retórica relacionada à base de conhecimento, no entanto, raramente especifica o caráter desse conhecimento. Não diz o que os professores deveriam saber, fazer, entender ou dizer que tornasse o ensino algo mais do que uma forma de trabalho individual, quanto mais ser considerado entre as profissões que requerem formação acadêmica. (Shulman, $2015^{2}$, p. 200)

Proposta inicialmente por Shulman $(1986,1987)$, e que tem como principal inovação a ideia de um Conhecimento Pedagógico de Conteúdo (no original, Pedagogical Content Knowledge - CPC). Segundo o autor, "entre essas categorias, o conhecimento pedagógico do conteúdo é de especial interesse, porque identifica os distintos corpos de conhecimento necessários para ensinar.” (Shulman, 2015, p. 205)

Os CPC, na interpretação deste autor, se caracterizam como a parte mais importante dentre os conhecimentos dos professores de determinado conteúdo, ou seja, dentre os conhecimentos que comporiam a BCE, os CPC representam aquele conhecimento que representa a atuação docente em conteúdo específico. Nessa linha de pensamento busca-se formar professores de Física que desenvolvam habilidades para o trato do "Conhecimento Pedagógico do Conteúdo" (Shulman, 1987). Na ideia original desse autor, os CPC incluem,

[...] a capacidade de um professor para transformar o conhecimento do conteúdo que ele possui em formas pedagogicamente poderosas e adaptadas às variações dos estudantes levando em consideração as experiências e bagagens dos mesmos (Shulman, 1987).

Em suma, a construção deste autor da taxonomia dos conhecimentos de professores reflete sobre o conhecimento do conteúdo específico e os conhecimentos pedagógicos que os professores constroem e/ou possuem. E derivam ainda da reflexão sobre a insuficiência desses conhecimentos para o processo de ensino-aprendizagem de conteúdos específicos, se entendidos como um conjunto de conhecimentos distintos que podem ser conectados ao longo do trabalho docente. Assim, na defesa do autor, além dos conhecimentos pedagógicos e dos conhecimentos de conteúdo específico, há de se desenvolver, entre professores, aquela base de conhecimento específico do profissional da educação que é denominado pelo autor como Conhecimentos Pedagógicos de Conteúdo.

Segundo Shulman (1986), o CPC é o que diferencia, por exemplo, um licenciado em Física de um bacharel em Física, pois somente o professor é o sujeito detentor deste conhecimento específico, aprimorado através da experiência, e nato da profissão. Para este autor, o CPC representa:

[...] uma mistura de conteúdo e pedagogia para a compreensão de temas, problemas ou questões particulares, os quais são organizados, representados e adaptados aos diversos interesses e habilidades dos alunos, para instrução [...] é a categoria mais provável para distinguir o especialista em conteúdo, do professor. (Shulman, 1987, p. 8, tradução nossa).

2 Lee S. Shulman, "KnowledgeandTeachingFoundationsofthe New Reform”, a Harvard EducationalReview, v. 57, n. 1, p. 1-22, primavera 1987 (Copyright bythePresidentandFellowsof Harvard College). Traduzido e publicado com autorização. Tradução de Leda Beck e revisão técnica de Paula Louzano. 
OsCPC contemplam, então, as diferentes maneiras de se abordar e apresentar os tópicos de uma área do conhecimento, de modo a torná-los mais compreensíveis para os alunos. Assim, o CPC abarca a compreensão do que facilita ou dificulta aprendizagem de um tópico, bem como a de que alunos de diferentes faixas etárias e portadores de diferentes experiências de vida trazem conceitos que podem interferir na aprendizagem desse tópico (Shulman, 1986).

Segundo Goes (2014), no ano de 2012, com a finalidade de encontrar um conceito comum para o CPC, a partir de uma conferência planejada para reunir os maiores pesquisadores internacionais, foi explorada a construção de uma concepção específica para o tema e um modelo único para ele. Na compreensão desta última, o CPC pode ser definido como "um conhecimento específico do professor que envolve, além do conhecimento das concepções dos alunos, o conhecimento das estratégias instrucionais de ensino, para ensinar e desenvolver a compreensão dos alunos de um conteúdo específico" (Goes, 2014, p.37).

Shulmam (1987) foi pioneiro em ter estabelecido as bases dos conhecimentos dos professores, e esta proposição se tornou objeto de estudo para as mais diversas áreas de formação de professores de conteúdo específico. Isto está relacionado principalmente com o fato de que o modelo dos conhecimentos de Shulman está baseado no ensino de conteúdos, e parte dos conteúdos a serem ensinados para construir os conhecimentos. Dessa maneira, o modelo proposto pelo autor despertou estudos e propostas nas mais diversas áreas das didáticas específicas, constituindo, até mesmo, um marco epistemológico para a construção de didáticas específicas.

Os estudos desenvolvidos por Shulman e colaboradores, especialmente no que diz respeito ao CPC, passaram a ser, segundo Bolívar (2005), um marco epistemológico privilegiado na investigação das didáticas específicas. Isso pode ser visto, por exemplo, em autores que se voltam para o ensino da área de ciências e de matemática: eles se debruçaram sobre o modelo original de Shulman e ampliaram-no tendo em vista as especificidades dessas áreas. (Almeida et. al., 2019, p. 133)

Desse ponto de vista, na reflexão de Bolivar (2005), o modelo de conhecimentos de Shulman reflete aspectos de uma didática específica, baseada no desenvolvimento de conhecimentos de professores, e relacionada ao ensino de conteúdos. Nessa perspectiva, práticas específicas de formação das mais diversas áreas vão se constituindo como diferentes elementos da base de conhecimentos, pois esses elementos são constituidores de distintos elementos do CPC em cada área. Dessa forma,

Ahorabien, a pesar de lasambigüedades y problemas que presenta a este nivel interno (Smith y Neale, 1989; Grossman, 1990), ladistinciónha resultado productivaprácticamente por supotencialidad para generar una investigación útil enlasdidácticas específicas para laformacióndelprofessorado. (Bolivar, 2005, p. 29)

Isso posto, torna-se evidente o fato de que muitas pesquisas foram realizadas com base na taxonomia dos conhecimentos de Shulman, aplicadas a campos específicos do ensino de conteúdos diferenciados. Dessa maneira, outros pesquisadores continuaram a discussão sobre esse tema e apresentaram investigações sobre processos 
formativos de professores de física se utilizando das três maiores categorias elaboradas por Shulman -CP (Conhecimento Pedagógico), CC (Conhecimento do Conteúdo), e CPC (Conhecimento Pedagógico o Conteúdo)-, tais como Etkina (2010), Melo-Niño et. al. (2016,2017), Lee e Luft (2008), Verdugo-Perona, Solaz-Portolés, \& San José-López (2016). Estes trabalhos se dedicam a investigar os conhecimentos da BCE que são específicos de professores de física e suas formas de construção. Nesse sentido a pesquisa aqui apresentada se enquadra dentro de uma linha de investigação sobre os conhecimentos de professores de física com base nos elementos de conhecimento de Shulman.

Etkina (2010), baseada nas teorizações promovidas por Magnusson, Krajcik,e Borko (1999), apresenta uma série de inovações no modelo do CPC proposto inicialmente por Shulman. A autora propõe um modelo formativo destinado aos professores de Física composto pelo: a) knowledge of content (CK) que abarca "os conceitos e leis da Física e os métodos da investigação científica” (p. 01, tradução nossa); b) general pedagogical knowledge (PK), caracterizado como sendo o "conhecimentos gerais sobre como as pessoas aprendem e sobre o funcionamento da escola” (p. 01, tradução nossa); c) pedagogical contente knowledge (CPC) como sendo um entendimento e uma habilidade que os professores de Física possuem para integrar os conhecimentos físicos à elementos que promovem e facilitam a aprendizagem dos estudantes.

A partir dessa classificação, o CPC dos professores de Física pode ser associado, por exemplo, aos métodos específicos de resolução de problemas físicos, à investigação experimental, ao conhecimento do currículo escolar de Física, às concepções de estudantes sobre os conceitos físicos, as estratégias que favorecem a mudança delas. Ou seja, o conhecimento pedagógico do conteúdo é, muito provavelmente, a categoria que melhor distingue a formação do professor de Física, do pedagogo e do físico profissional (Shulman, 1987; Etkina, 2010).

Mais além, Melo-Niño, Cañada y Mellado (2016), se utilizaram desse conjunto de conhecimentos para avaliar o processo de formação de professores de Física sobre eletricidade, concluindo principalmente que a imagem que os professores apresentam dos próprios CPC são diversas, alimentando a reflexão sobre a necessidade de haver mais detalhamentos sobre os conhecimentos da base para cada conteúdo. Em outra pesquisa, Melo-Niño et. al. (2016) se debruçam sobre os subdomínios do CPC para, então, avaliar os conhecimentos de professores de Física a respeito da ideia de carga elétrica. Os autores concluem que:

Por otro lado la tendencia predominante los dos años consecutivos sobre la idea de enseñanza, aprendizaje y conocimiento curricular es la tradicional. Sin embargo, frente a la naturaleza de las ideas de los estudiantes es la tendência constructivista la que predomina y en las categorías conocimiento sobre la evaluación y las estrategias de enseñanza, se presenta una mezcla entre tendencias. (Melo-Niño et. al., 2016, p. 471)

Ou seja, diante dessa compreensão conceitual da questão dos conhecimentos de professores e das diversas pesquisas que buscam sistematizá-los no caso dos futuros professores de física, o que se pode inferir é que os mais diversos modelos compreensivos contribuem com as especificidades da discussão ao analisarem processos de formação de professores de física a partir das categorias de conhecimento origi- 
nais. Contudo, o fato de todos eles se basearem fundamentalmente nos trabalhos de Shulman $(1986,1987,2004)$ para a reconstrução e especificação dos conhecimentos, nos enseja a afirmação da importância conceitual que os conhecimentos fundantes dessa discussão ainda são pertinentes como categoria geral e para a análise de processos formativos de professores

A partir do exposto em relação aos diversos modelos de CPC existentes, neste trabalho optamos por ter por referência básica a construção do CPC de licenciados em Física que participam do desenvolvimento de atividades educativas elaboradas por meio de uma parceria estabelecida com um professor de Física de uma escola de Educação Básica, tendo como referencial de análise as concepções presentes no modelo original de Shulman (1986), considerado por nós mais simples e adequado para as análises realizadas nesta investigação. Nesse sentido, os dados da pesquisa serão analisados tendo como base o grande conjunto categórico oriundo de Shulman e aplicado ao conteúdo de física, que pode ser representado como no Quadro 1, a seguir:

\section{Quadro 1: Resumo das categorias de conhecimento que seráo utilizadas para análise dos dados.}

\begin{tabular}{|c|c|}
\hline $\begin{array}{l}\text { Categoria de Con- } \\
\text { hecimento }\end{array}$ & Descrição \\
\hline $\begin{array}{l}\text { Conhecimento de } \\
\text { Conteúdo (CC) }\end{array}$ & $\begin{array}{l}\text { Conjunto de conhecimentos relacionados ao conteúdo específico de Física, } \\
\text { tanto em linguagem universitária, quanto em linguagem da educação básica. } \\
\text { Trata-se de demonstrar conhecimento sobre o conteúdo a ser ensinado. } \\
\text { Fazem parte desse grupo de conhecimento, por exemplo:a.) Conhecimento } \\
\text { das leis da física e das grandezas fundamentais; b.) Conhecimento das rela- } \\
\text { ções conceituais e matemáticas entre os conceitos e grandezas da física; c.) } \\
\text { Conhecimento do processo de construção das leis da física e como a ciencia } \\
\text { constrói conhecimentos; d.) Conhecimentos sobre os processos de constru- } \\
\text { ção de conhecimento físico de base experimental. }\end{array}$ \\
\hline $\begin{array}{l}\text { Conhecimento } \\
\text { Pedagógico (CP) }\end{array}$ & $\begin{array}{l}\text { Trata-se do conjunto de conhecimentos da pedagogia geral, das teorias de } \\
\text { aprendizagem e do funcionamento dos sistemas de ensino. Fazem parte des- } \\
\text { se grupo de conhecimento, por exemplo: Conhecimento sobre o funciona- } \\
\text { mento da escola, gestão e organização da escola. Conhecimento das formas } \\
\text { de aprendizagem dos alunos e suas diversidades cognitivas. Conhecimento } \\
\text { sobre as fundamentações teóricas dos processos educativos, fundamental- } \\
\text { mente os valores que cercam o processo educativo. Conhecimento sobre } \\
\text { estratégias gerais de ensino, tais como grupos de trabalho, aprendizagem } \\
\text { colaborativa, etc }\end{array}$ \\
\hline $\begin{array}{l}\text { Conhecimento } \\
\text { pedagógico de Con- } \\
\text { teúdo (CPC) }\end{array}$ & $\begin{array}{l}\text { O CPC, como jádito, é o tipo de conhecimento específico para o ensino } \\
\text { de física, neste caso. Trata-se da articulações entre os conhecimentos de } \\
\text { conteúdos e os conhecimentos para o ensino, específicamente relacionado } \\
\text { aosconteúdos de física. Fazem parte desse grupo de conhecimento, por } \\
\text { exemplo: Conhecimento sobre métodos e abordagens de ensino de física, } \\
\text { tais como experimentação e investigação, abordagem temática ou CTS, } \\
\text { etc; Conhecimento sobre o currículo de física e os conceitos físicos em } \\
\text { linguagem escolar; Conhecimento dos materiais didáticos e instrumentos } \\
\text { específicos do ensino de física; Conhecimento das concepções e dificuldades } \\
\text { mais comuns dos alunos em diversos conceitos físicos; Conhecimento de } \\
\text { métodos de avaliação específicos que captem a manifestação das relações } \\
\text { entre conceitos e do pensamento físico nos alunos. }\end{array}$ \\
\hline
\end{tabular}

Fonte: Elaborado pelos autores 
Baseado na discussão apresentada e na definição das categorias de conhecimentos de Shulman como um elemento avaliativo de processos formativos de professores de física, construímos a seguinte questão de pesquisa: que elementos da base de conhecimento do professor sáo explicitados por licenciandos ao longo de um processo de elaboraçáo e aplicaçáo de atividades pedagógicas que envolve a parceria com uma professora de Física da escola básica?

Ainda, é importante destacar que essa parceria trata da construção e a aplicação de atividades pedagógicas voltadas para alunos do Ensino Médio de escolas públicas de um município do estado de Minas Gerais.

\section{Procedimentos Metodológicos}

Esta pesquisa é de natureza qualitativa e foi realizada a partir da parceria estabelecida entre licenciandos em Física e uma professora de Física da educação básica. Esta professora possuía, no momento desta investigação, mais de 10 anos de efetiva atuação profissional. Dessa maneira, a atividade formativa, ou seja, a prática de formação de professores que está sendo implementada e avaliada nesta pesquisa, é o desenvolvimento de sequencias de aula em parceria entre estudantes de licenciatura em física e uma professora da educação básica.

O contexto da realização desta pesquisa está relacionado com atividades pedagógicas que envolvem licenciandos dos cursos de Física e Matemática que são bolsistas de um programa institucional PET (Programa de Educação Tutorial), alunos da educação básica e uma professora de Física da escola pública. A universidade envolvida neste contexto possui um centro de divulgação científica que atende escolas da sua região de influência. Dentre as atividades que ocorrem neste centro de divulgação científica se destacam aquelas no qual licenciandos e professores da educação básica se reúnem para planejar e executar atividades pedagógicas em conjunto. Essas atividades se apresentam como processos de formação em conjunto e, de modo especial, têm viabilizado processos formativos diferenciados para um grupo de licenciandos dessa universidade.

Além do centro de divulgação científica, também está à disposição do grupo formado por licenciandos e professores da educação básica os laboratórios didáticos de Física (LDF) da universidade. Neste sentido, algumas das atividades planejadas são frequentemente realizadas com o apoio da infraestrutura da universidade. Nesse contexto, uma professora da educação básica foi convidada para se reunir com os licenciandos em física durante um período e elaborar atividades em conjunto que pudessem ocorrer na escola e na universidade e que visassem criar um conjunto de aulas -sequencia didática- que englobassem atividades experimentais ocorridas na universidade, além odo espaço do centro de ciências.

A partir desse contexto, foi elaborado um processo de acompanhamento e investigação das atividades conduzidas pelo grupo formado por licenciandos e uma professora de Física que atua na educação básica. Foram acompanhados e registrados cinco encontros, nos quais esse grupo discutiu e planejou atividades pedagógicas de Física voltadas aos alunos de escolas públicas do ensino médio. Foi possível acompanhar a discussão sobre os temas e os conteúdos a serem trabalhados com os alunos da educação básica, a escolha das propostas experimentais a serem desenvolvidas no LDF e no Centro de Ciências, o papel dos licenciandos, o papel dos professores da educação básica e as resoluções do grupo acerca das datas dos encontros. 
Os temas e conteúdos foram escolhidos na primeira reunião do grupo. Ou seja, a partir da definição dos locais onde ocorreriam os encontros, foi então formado um grupo de planejamento conjunto de atividades experimentais, constituído por licenciandos e uma professora de Física da educação básica. Os licenciandos escolhidos para integrar este grupo de planejamento junto com a professora da educação básica foram alunos do curso de licenciatura em física em estágio avançado de formação (último ano do curso). Isso é importante pois os licenciandos deveriam, ao menos já ter estudado todos os conteúdos de física básica.

São denominados ALF1 e ALF2 os dois alunos de licenciatura em física que integraram o grupo e ambos participaram do planejamento e da execução de um conjunto de aulas experimentais, desenvolvidas na universidade e direcionada aos alunos da professora da educação básica. O tema das aulas foi mecanica básica, mais fundamentalmente os conteúdos de velocidade e aceleração.

Os planejamentos desenvolvidos nesse contexto, assim como a aplicação da atividade planejada com alunos do primeiro ano do Ensino Médio, são objeto de estudo nesta pesquisa, com foco nos licenciandos e nos conhecimentos expressos por eles ao longo de todo o processo. O Quadro 2 apresenta um cronograma das atividades realizadas e que foram objeto de análise nesta pesquisa.

\section{Quadro 2: Momentos da proposta que foram registrados para construçáo dos dados da pesquisa}

\begin{tabular}{|l|l|l|}
\hline \multicolumn{1}{|c|}{ Momento } & \multicolumn{1}{|c|}{ Ações } & \multicolumn{1}{c|}{ Objetivos } \\
\hline Planejamento & $\begin{array}{l}\text { 5 encontros entre os licenciandos e a } \\
\text { professora da educação básica }\end{array}$ & $\begin{array}{l}\text { Discutir e produzir, em conjunto, uma } \\
\text { atividade didática para ser desenvolvida } \\
\text { em uma turma de Ensino Médio }\end{array}$ \\
\hline Execução & $\begin{array}{l}\text { 2 atividades de execução das pro- } \\
\text { postas planejadas em conjunto pelo } \\
\text { grupo }\end{array}$ & $\begin{array}{l}\text { Realizar, em parceria entre a docente e os } \\
\text { licenciandos, as atividades planejadas. }\end{array}$ \\
\hline Avaliação & $\begin{array}{l}1 \text { encontro geral de avaliação dos } \\
\text { resultados e possível reestruturação da } \\
\text { proposta }\end{array}$ & $\begin{array}{l}\text { Discutir os acertos e equívocos na } \\
\text { execução das atividades e produzir } \\
\text { adaptações para a melhoria destas. }\end{array}$ \\
\hline
\end{tabular}

Fonte: Elaborado pelos autores

Relatadas as atividades que foram sistematicamente acompanhadas e analisadas, destacamos que os sujeitos desta pesquisa são dois licenciandos em Física -ALF-1 e ALF-2 -que ingressaram no curso de licenciatura em Física, respectivamente em 2015 e 2013.

Com relação ao ALF-1, antes do seu ingresso na universidade, tinha concluído um curso técnico em Eletricidade, com ênfase em Automação e Controle de Processos e após seu ingresso, logo no primeiro semestre, participou do processo seletivo para o Programa Institucional de Bolsas de Iniciação à docência (PIBID), tendo permanecido neste programa por um semestre. Ao final desta etapa, entrou no PET -Licenciaturas, através de processo seletivo, sendo aceito na modalidade de bolsista. Com relação ao ALF-2, a aluna ingressou na universidade em 2013 e terminou sua graduação no ano de 2016, participando do PET-Licenciaturas e atuando como mediadora em um centro de ciências, recebendo alunos para visitas que ocorreram no espaço no período de 2014 à 2016. Além disso, ainda participou de atividades que ocorreram nos LDF nesse período. 
Ressaltamos que a parceria entre os licenciandos e a professora se constituiu como projeto de formação executado junto ao centro de ciências da universidade e que os planejamentos foram realizados para que ocorressem no centro de ciências e no LDF da universidade, mas sempre nos horários de aula da professora na escola. Durante a definição dos conteúdos que seriam abordados nas atividades, a partir das demandas da professora da educação básica, optou-se por trabalhar, respectivamente, com uma turma do ensino médio o tema queda livre e com outra turma do ensino médio o tema movimento, força e energia. Tanto os conteúdos quanto as ações didáticas que seriam necessárias para abordá-los foram objeto de discussão e construções conjuntas tendo, ALF1 e ALF2 como participantes.

Os dados desta investigação foram obtidos por meio da gravação em áudio dos encontros de preparação e aplicação das atividades didáticas entre os licenciandos e a professora da educação básica. Além disso, realizou-se uma entrevista e a aplicação de um questionário junto aos dois licenciandos. A entrevista com os licenciandos foi realizada após a aplicação da atividade. As entrevistas foram gravadas em vídeo, sendo que as perguntas foram construídas através de um roteiro inicial e aplicadas na sequência proposta. Os dados dessas fontes foram analisados nos termos das categorias apresentadas no Quadro 1.

A categoria "CC está relacionada aos conhecimentos específicos de Física descritos pelos licenciandos. A categoria CP, com base nos referenciais previamente apresentados, identifica os fundamentos pedagógicos expressos pelos licenciandos e a fundamentação que eles atribuíram a cada um deles. A categoria CPC está relacionada com a compreensão dos licenciandos em relação as diferentes articulações entre os elementos anteriormente descritos; ou seja, àqueles elementos mais necessários dentre os conhecimentos dos professores de conteúdos específicos.

Para realizar a análise, as entrevistas e os questionários foram transcritos na integra. Após isto foram realizadas várias leituras com a finalidade de identificar agrupamentos relacionados com as categorias dadas a priori. A partir das categorias procuramos identificar e compreender as formas como os licenciandos organizam o conteúdo para o ensino, como propõe apresenta-los para os alunos, e como eles o adaptam para a linguagem escolar, visando o ensino desses conteúdos.

Os resultados encontrados na análise dos dados serão apresentados na sequência de forma individual - para cada licenciando participante - o que permitirá discutir cada uma das categorias e agrupamentos apresentados por eles.

\section{A construçáo da Base de Conhecimento para o Ensino de profes- sores: o trabalho colaborativo entre licenciandos e professores da educaçáo básica}

Com base nas argumentações realizadas anteriormente e nos passos metodológicos elencados, apresentamos a discussão dos principais resultados a respeito das categorias de conhecimentos identificadas nas transcrições das entrevistas e nas respostas apresentadas pelos licenciandos às perguntas do questionário. Ressaltamos 
também que as principais unidades de registro que expressam os resultados foram compiladas, de modo que são apresentados aqui, por meio de excertos, exemplos representativos para as análises segundo sua relevância para a compreensão do processo e não em ordem cronológica de análise. Em cada excerto serão destacados os trechos que foram utilizados para a classificação nas categorias.

Foram analisadas as falas dos licenciandos que participaram do projeto de planejamento conjunto em parceria com uma professora da educação básica, a fim de expressar as características ou indícios de construção da base de conhecimento do professor nessas falas.

\section{Conhecimento de Conteúdo (CC)}

No caso de ALF-1, a atividade elaborada em conjunto com a professora da educação básica diz respeito ao tema queda livre, intitulada "Queda livre de Corpos". Esta foi desenvolvida com alunos de primeiro ano do ensino médio. $\mathrm{Na}$ análise desta elaboração foi possível identificar manifestações de conhecimento relativas a algumas grandezas físicas, tais como posição, velocidade, tempo, aceleração e massa, que foram destacadas pelo licenciando para caracterizar o objetivo central da atividade, que era mostrar que corpos iguais e de massas diferentes caem em tempos iguais. Das respostas apresentadas por ele às questões do questionário, destacamos os excertos a seguir:

E1: O objetivo foi mostrar para eles sobre a queda de corpos iguais e massas diferentes, o que aconteceria. (ALF-1)

E2: Mostrar que não há relação entre o tempo de queda e a massa de um corpo que está em queda livre. Que o atrito com o ar e a geometria do corpo influencia no tempo de queda.(ALF-1)

Os excertos acima mostram que o ALF1 se preocupou em discutir os conteúdos que foram trabalhados na atividade, utilizando as grandezas massa e tempo para caracterizá-lo. Além disso, ele também mostrou aspectos relacionados ao CC ao manifestar que, se não estiver em queda livre, o atrito com o ar, a geometria do corpo e a massa do corpo são grandezas que interferem no tempo de queda do mesmo.

Além dos excertos E1 e E2, relacionados à atividade "queda livre de corpos", o ALF1 também se manifestou quando lhe foi perguntado que conceitos físicos foram discutidos no planejamento das atividades. Os excertos selecionados manifestados por ele nesta ocasião foram:

E3: Produçâo e conservaçâo de energia: mostrar como se dá a produçâo de energia, a energia ela é produzida de diversas formas diferentes, sendo que ela pode ser convertida em outra forma de energia. (ALF-1)

E4: Circuitos elétricos: Estudar alguns componentes de um circuito elétrico, que éo conjunto de vários componentes, como por exemplo, uma fonte de tensão e resistores elétricos. Estudar principalmente a relação entre corrente elétrica, tensáo elétrica e resistência elétrica.(ALF-1) 
E5: Foram várias atividades, em uma delas trabalhamos com Corrente elétrica, que é um fluxo ordenado de elétrons, com Tensão elétrica, que é a força que "empurra" esses elétrons e a resistência elétrica que é uma dificuldade imposta por um determinado material aos elétrons. Todas essas grandezas se relacionam, pois todas fazem parte e estão presente em um circuito elétrico, por exemplo.(ALF-1)

Apesar da analogia utilizada por ALF1 no excerto E5 (atensão elétrica é a força que empurra esses elétrons), é possível verificar que o ALF1 mostra aspectos relacionados ao CC no planejamento das atividades em conjunto com a professora da educação básica.

O licenciando ALF2, que desenvolveu seu trabalho no centro de ciências da universidade, salientou que o trabalho colaborativo realizado por ele no centro de divulgação científica foi e esteve voltado para a condução de alunos para a execução de experimentos ligados à área de Mecânica. De acordo com o licenciando, nesse centro de divulgação científica foram trabalhados os seguintes conteúdos específicos com os alunos do ensino médio: movimento, força e energia.

De acordo com as respostas apresentadas por ALF-2 às perguntas do questionário, foi possível perceber que o trabalho pedagógico com o conteúdo movimento esteve relacionado exclusivamente com a descrição do mesmo (cinemática), sem se importar com as suas causas (dinâmica). Entretanto, no questionário o licenciando ALF-2 apresentou considerações sobre o estudo do Movimento Retilíneo Uniforme (MRU) e o Movimento Retilíneo Uniformemente Variado (MRUV). Segundo este licenciando, esse conteúdo específico de Física já havia sido estudado por ele em disciplinas do curso.

E6: Massa é uma caracteristica intrínseca dos corpos, que permite interação com outros corpos com essa mesma propriedade, definida como interaçáo gravitacional. (AFL-2)

E7: Velocidade é a variação da posição de um corpo com relaçấo ao tempo. Aceleraçâo é a variação da velocidade de um corpo com relaçáo ao tempo. (AFL-2)

E8: Um conceito, por exemplo, que na atividade foi trabalhado, foi o de força centrípeta e a pseudoforça centrifuga, nessa situação, não que eu entendesse os conceitos de forma diferente, mas utilizamos um experimento que usualmente utilizávamos na explicação da conservação do momento angular, para explicar força centripeta.(AFL-2)

O licenciando ALF-2 apresentou no questionário considerações sobre o propósito da atividade e a forma como os conceitos de Física foram abordados. Ao descrever as grandezas que deram suporte aos conteúdos discutidos na atividade ele apresentou as definições com precisão. Os dados indicam que o licenciando apresentou as definições de velocidade e aceleração contendo os mesmos elementos presentes nos livros do Ensino Médio (EM) e do Ensino Superior (ES).

Ao definir a grandeza massa, o licenciando ALF-2 apresentou o conceito como algo que é próprio do objeto, ressaltando sua influência na interação gravitacional entre dois corpos que possuem massa. Outro ponto em destaque foi o fato dele ter apresentado dois conceitos distintos que sempre não são simples de serem entendidos pelos estudantes do ensino básico: força centrípeta e a pseudoforça centrífuga. 
A partir da sua afirmação e das definições encontradas nos livros de EM e do ES, percebe-se que o conceito apontado por ele traz elementos da base de conteúdo específico apresentados na disciplina de Física-1

Nesse contexto, parece-nos evidente que os dois licenciandos possuem conhecimentos básicos sobre conceitos da Física. Por básico, nesse caso, entendemos a apropriação dos conceitos e sua aplicação em situações amplamente estudas no curso. Nos dois casos os licenciandos demonstravam confiança em lidar com conceitos de Física, sobretudo porque estes estavam relacionados com temas da Mecânica. Estes temas costumam ser amplamente estudados, geralmente no primeiro ano, pelos licenciandos em Física em seus cursos de licenciatura.

Um bom exemplo deste conhecimento em Física dos estudantes se relaciona com o fato de que ao expressar-se sobre o tema queda livre, ALF-1 indica que não há relação entre o tempo de queda de um corpo, sua massa e seu formato, a não ser que haja resistência do ar. Na entrevista ALF-1 menciona:

\section{E9: [...] olha só, não há relação entre o tempo de queda e a massa de um corpo que está em queda livre. Dá para mostrar isso pedindo para eles compararem o tempo de queda com os tipos de bolinhas. (ALF-1)}

A partir do excerto anterior, percebemos a preocupação do ALF-1 em mostrar que a geometria do corpo e a aceleração gravitacional são grandezas que interferem na queda do mesmo. Nesse caso, é possível perceber que o licenciando discutiu os conteúdos trabalhados na atividade "Queda livre de corpos", utilizando as grandezas massa e tempo para caracterizá-lo. Entretanto, ele não o definiu objetivamente, optando por discutir conceito de queda livre a partir da pergunta inicial proposta no roteiro da atividade.

\section{Conhecimento Pedagógicos de Conteúdo e sua Articulação com Conhecimentos de Conteúdo Específico}

Neste item destacamos e discutimos aqueles momentos presentes nas entrevistas ou nas gravações do planejamento conjunto, nos quais os Licenciandos ALF-1 e ALF-2 expressam não somente os conhecimentos específicos de Física, mas aqueles relativos às estratégias de ensino de Física, às articulações entre os CC e as formas de promover o ensino desses conteúdos CP. A isso, como já dito, chamamos aqui de CPC.

Chamou nossa atenção que o licenciando ALF-2, ao descrever na entrevista a fundamentação pedagógica do trabalho que estava sendo planejado, citou explicitamente que este se apoiava no construtivismo. Ele apontou ainda a aproximação do conteúdo de Física a ser desenvolvido com aspectos do cotidiano dos alunos:

E10: A ideia da atividade foi retomar os conceitos que eles já haviam visto com a professora (movimentos), e introduzir de uma forma mais conceitual os demais (energia e forcas), assim a ideia foi trabalhar os conceitos de forma mais cotidiana, utilizando exemplos do dia-a-dia, para que depois ela pudesse formalizar esses conteúdos em sala de aula, retomando as atividades construidas/realizadas aqui com os alunos. (ALF-2) 
Outro aspecto que chamou nossa atenção está relacionado às considerações de ALF-1 sobre a perspectiva do processo de aprendizagem promover a mudança de uma concepção alternativa do aluno. De acordo com o que foi explicitado por ALF-1 ao longo da entrevista, os alunos deveriam responder uma pergunta para depois realizar as medidas e cálculos cujo intuito era mudar sua concepção inicial. Isso pode ser melhor visualizado a partir de um excerto retirado da entrevista:

E11: [...] a gente elaborou algumas perguntas antes de começar o experimento, que levasse o aluno a pensar um pouco, se é isso mesmo, ou se ele ia responder sobre tal pergunta partindo do senso comum, ou se ia ter um pensamento diferente. E [...] no decorrer do roteiro, a gente foi fazendo mais perguntas e no meio das perguntas ele fazia medida e realizava uma atividade. Eno final, a gente realizava a mesma pergunta que tinha feito no começo, para ver se ele entendeu o que a gente queria passar.(ALF1)

A partir desse excerto podemos indicar que o licenciando procurou organizar com a professora da educação básica uma atividade com o objetivo de fazer um levantamento das concepções alternativas dos estudantes sobre a queda livre de corpos de massas diferentes. Em seguida, o licenciando ALF-1 e a professora da educação básica solicitaram dos estudantes medições de posição e tempo, para encontrar os valores de distância e tempo decorrido, e através deles calcular a velocidade e aceleração das bolinhas. Ainda segundo o relato do ALF-1, no final da atividade proposta, pela comparação dos valores de tempo e aceleração de cada uma das bolinhas, os alunos do ensino médio conseguiram responder novamente à pergunta inicial e mudar o entendimento que tinham sobre a queda livre de corpos de massas diferentes.

O licenciando ALF-2, por sua vez, descreveu a atividade realizada por ele e a professora da educação básica apontando elementos da sua construção através da apresentação das etapas de construção e os papeis de cada um dos integrantes da proposta. Com isso, ele apresentou conhecimento e visão do que foi desenvolvido na proposta, como pode ser visto no excerto a seguir retirado da transcrição da entrevista:

E12: Foi um trabalho interessante, pois nós começamos a nos reunir com antecedência. E ela trouxe para nós o plano do curso dela, pensou com a gente se ela traria os alunos antes de terminar o conteúdo. A gente foi planejando inicialmente. [...] E ai a gente foi pensando junto, foi vendo as necessidades da visita e do laboratório. Nós tinhamos interesse que ela ficasse no laboratório sendo um fato interessante, pois ela participou bastante, e também a gente desenvolveu um roteiro para aplicarmos aos alunos inicialmente. (ALF-2)

Pela descrição anterior, o ALF-2 indica que a atividade planejada o auxiliou a construir conhecimentos de como estruturar atividades pedagógicas voltadas para alunos do Ensino Médio. O excerto a seguir, também retirado da transcrição da entrevista, apresenta outro relato que aponta para o aprendizado do licenciando voltado para o planejamento de atividades pedagógicas:

E13: [... nós tivemos que repensar boa parte dos experimentos. Tivemos que abordar os experimentos de forma que pudesse atender o conteudo que os alunos estavam tendo contato em sala de aula naquela etapa do ano letivo. (ALF-2) 
Mesmo com esta adaptação, o licenciando ALF2 descreve na entrevista uma dificuldade significativa e importante que interfere na forma como o conteúdo de Física foi apresentado para os alunos, que se remete a questão da utilização de termos específicos da Física com os alunos do Ensino Médio. Segundo o ALF-2, havia uma dúvida que surgiu pelo emprego de alguns conceitos para justificar os experimentos, já que não era sabido se os alunos tinham conhecimento de alguns deles. Com isto, a preocupação com a menção a esses conceitos foi constante, como é descrito no excerto a seguir:

\section{E14: Acho que uma dificuldade que tive esteve associada ao fato de que não sabia se podia falar sobre alguns conceitos mais especificos.(ALF-2)}

A preocupação com a adequação da apresentação dos conceitos de Física para os alunos do Ensino Médio também foi explicitada na entrevista por ALF-1. Os dados indicam que ele buscou adequar a linguagem do roteiro da atividade experimental ao publico presente.

E15: Acho que o grande diferencial deste trabalho foi o roteiro. A gente náo pegou nenhum roteiro pronto, a gente bolou o roteiro do zero, pensando numa linguagem diferente e tentando fazer o roteiro de forma que ele fosse um diálogo com o aluno.(ALF-1)

E16: Pensei em criar um roteiro que de certa forma conversasse com o aluno, e não fosse uma receitinha de bolo. Tentei deixar o roteiro da forma mais simples possivel e que o aluno sempre tivesse que participar respondendo perguntas e até mesmo desenhando algumas coisas. Pensei sempre em começar o roteiro com uma pergunta chave, e no final do mesmo, realizar novamente a mesma pergunta, com a ideia de analisar a diferença entre as suas respostas. (ALF-1)

O licenciando procurou apresentar informações mais conceituais da Física a partir da descrição de aspectos do cotidiano do estudante. Este momento destacado se relaciona a um elemento do CPC, a saber, a busca por estratégias específicas de construção do conceito juntamente aos alunos.

Saindo do contexto do planejamento do roteiro e focando nas estratégias utilizadas na atividade experimental, o licenciando ALF-1 aponta na entrevista que o trabalho com o professor da educação básica lhe propiciou uma oportunidade para criar um repertório para explicar os conteúdos de Física trabalhados na educação básica. Outro aspecto relevante do trabalho conjunto entre os licenciandos e a professora da educação básica se volta para as discussões que esses tiveram sobre as inúmeras adaptações que precisaram ser realizadas no momento que a atividade pedagógica foi levada para uma situação real de ensino-aprendizagem. Neste contexto, AFL-1 relatou na entrevista um momento de adaptação na atividade ocasionada pela falta de tempo para finalizar o que havia sido proposto, tendo que modificá-la. Aliás, a atividade não foi executada na íntegra:

E17: [...] é que o tempo foi bastante escasso, foi uma coisa que atrapalhou, a gente náo conseguiu atingir tudo que a gente queria com o roteiro. A gente teve que passar mais rápido por determinada parte, ou não fazer determinada parte.(ALF-1) 
Como alternativa para concluir a atividade, AFL-1 optou, em conjunto com a professora, por reduzir a quantidade de dados solicitados aos alunos para concluírem a atividade experimental.

O licenciando ALF-2 também relatou ter construído frequentes diálogos com a professora com o objetivo de melhor adaptar o conteúdo específico de Física à turma de alunos do Ensino Médio. O licenciando afirmou ter sido esse um momento importante para sua formação docente. O excerto a seguir foi retirado da entrevista e exemplifica parte desse relato:

E18: Nós aprendemos novos meios de tratar os mesmos experimentos, porque nós não temos experimentos que abordem todos os conteúdos. Aí nós tivemos que repensar boa parte dos experimentos, abordar os experimentos de forma que venha a atender o conteúdo que os alunos estão vendo em sala de aula. Isto foi um aprendizado exclusivo, pois tivemos que olhar para aquilo de forma diferente até para nossa própria prática, pois geralmente olhamos o experimento só de uma forma e acabamos vendo novas formas de trabalhá-lo em outro contexto, e isto facilita inclusive a aprendizagem do aluno. (ALF-2)

O licenciando ALF-2 citou ainda o aprendizado que foi construído junto com a professora ao debaterem o experimento do Giroscópio, aqui representado por uma corda presa a uma roda de bicicleta, conforme ilustrado na Figura 1.

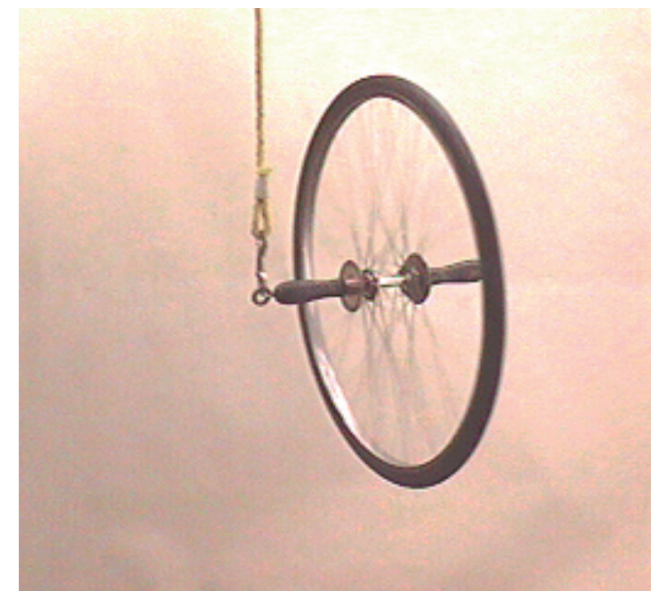

Figura 1: Giroscópio - Exemplo de experimento semelhante ao desenvolvido na atividade Fonte: ALVARENGA, Beatriz, MÁXIMO, Antonio. Curso de Física Volume 1. São Paulo, Ed. Scipione, 2000 .

Segundo o ALF-2, o experimento foi reestruturado de forma que o conceito de força centrípeta fosse apresentado durante o experimento, aproveitando apenas o movimento circular da roda. $\mathrm{O}$ excerto retirado da entrevista ilustra essa situação:

E19: Um conceito, por exemplo, que na atividade foi trabalhado, é o de força centrípeta e a pseudo força centrifuga. Nessa situação, não que eu entendesse os conceitos de forma diferente, mas utilizamos um experimento que usualmente utilizávamos para a explicação de torque e momento angular. Utilizamos ele para explicar força centripeta. Isso exigiu uma abordagem do experimento com outro olhar. Fizemos uma tentativa de explicar como essa força atuava naquele experimento. Construi- 
mos um olhar para o conceito de forma diferente. No caso, o experimento era uma roda de bicicleta que ao ser girada e segurada por uma corda presa em seu eixo principal não caía na horizontal. Tivemos que pensar em como a força centripeta pode ser utilizada para explicar esse fenômeno, no caso a componente das forças atuando na roda girando davam uma condição de equilibrio para roda naquela posição, diferente de quando ela náo gira. A mudança do pensamento sobre o conceito, foi sair de uma teorização descritiva, ou matemática e aplicá-la em uma situação cotidiana. (ALF-2)

Pode-se perceber que o licenciando tentou discutir o conceito de força centrípeta a partir da adaptação de uma atividade experimental previamente construída para abordar o conceito de torque e momento angular. Nesse sentido, percebemos que o licenciando foi capaz de realizar, com a colaboração da professora, algumas adaptações na abordagem do que estava sendo ensinado. Entretanto, percebe-se do excerto que a explicação física que ele apresentou para discutir o experimento está equivocada fisicamente.

Verifica-se, então, um forte "traço" do conhecimento pedagógico do conteúdo, em que este licenciando articula o conteúdo específico para fins de ensino de forma que transforme o conteúdo em algo pedagogicamente claro para um aluno de Ensino Médio. Todavia, o conhecimento de conteúdo específico que o aluno apresenta não foi suficiente para uma abordagem conceitualmente correta do ponto de vista da Física.

Importante ainda ressaltar novamente queo ALF-2 apresenta em seu discurso diferentes considerações que podem ser ligadas diretamente aos conceitos e práticas construtivistas. Termos tais como "conhecimento prévio dos alunos" e "mediação" indicam que o licenciando acessa em seu discurso termos característicos do construtivismo piagetiano e do sócio construtivismo vigotskyniano.

Consideramos que os licenciandos que participaram dessa investigação se apropriaram de alguns termos pedagógicos provenientes da leitura dos artigos que eles tiveram e têm contato ao longo do processo de formação inicial no curso de licenciatura. É significativo que os licenciandos lancem mão de termos como mediação quando tratam do processo de aprendizagem dos alunos da educação básica. Parece-nos evidente que esse conhecimento de natureza mais pedagógica foi fundamental para o licenciando estabelecer uma conversa mais profícua com a professora da educação básica que atuou na construção conjunta de atividades pedagógicas.

Esse conhecimento de natureza mais pedagógica está presente no discurso dos licenciandos e também parece ter sido utilizado na construção de suas práticas pedagógicas. O licenciando ALF-2, por exemplo, diz ter confrontado as concepções alternativas dos alunos do Ensino Médio com os dados obtidos em uma atividade experimental ocorrido nas dependências da universidade. Para isso, na elaboração do roteiro, ele utilizou uma linguagem menos técnica e mais informal, que objetivou tornar o aluno do Ensino Médio mais ativo na execução do experimento. $\mathrm{Na}$ aplicação, no momento destinado à compreensão e ao cálculo das grandezas físicas utilizadas na descrição do fenômeno estudado no experimento, ele utilizou estratégias que permitiram a contextualização do fenômeno. Ao fim, durante a aplicação, ele teve que fazer escolhas e promover a adaptação do conteúdo para atingir o objetivo final do roteiro. 
Nesse sentido, a manifestação do CP também aparece para ambos os licenciandos quando eles relatam ter percebido um problema relacionado ao funcionamento, gestão e organização da escola. Para eles, a questão da locomoção escola-faculdade e faculdade-escola e o desinteresse de alguns alunos foram obstáculos que tiveram que ser superados. Relatam, entretanto, o papel da professora da educação básica na realização das atividades.

E20: Porém, a gente foi surpreendido, ela participou bastante, ela foi bastante ativa, e isto não foi um problema. (ALF 1)

E21: [...] a ficou eu achei que a presenca dela, como a gente tinha planejado, e ela participou bastante, eu achei que foi fundamental a participação dela porque ela ajudou mesmo a gente. (ALF 2)

Dessa maneira, os resultados aqui apresentados denotam um processo de expressão dos conhecimentos da BCE por futuros professores de física quando desenvolvem uma atividade de construção conjunta de aulas experimentais de física em parceria com uma professora da educação básica

\section{Consideraçóes finais}

Este trabalho teve como objetivo analisar elementos da Base de Conhecimentos para o Ensino que estiveram presentes nas manifestações de alunos que participaram de propostas pedagógicas elaboradas e aplicadas em colaboração com professores da educação básica.

$\mathrm{Na}$ construção desta investigação foram analisados os dados provenientes das gravações em áudio de um planejamento colaborativo, uma entrevista e um questionário realizado com os licienciandos participantes de tal planejamento. Para analisar os dados foram criadas três categorias: conhecimento do conteúdo, conhecimento pedagógico e conhecimento pedagógico do conteúdo. Com elas, foram identificados elementos que mostraram as possíveis contribuições que a proposta trouxe para formação destes licenciandos.

Os excertos elencados e discutidos aqui permitem explicitar a BCE que os licenciandos possuem e como estes podem ser desenvolvidos a partir de um trabalho colaborativo entre professores em atividade e em formação inicial. Por exemplo, foi possível perceber que o licenciando ALF-2, possivelmente por estar nos semestres finais do curso e pela experiência adquirida como monitor em um centro de ciências, conseguiu trabalhar os conteúdos abordados na atividade realizada de forma mais elaborada, mesmo tendo apresentado dificuldades na discussão do conceito de força centrípeta.

A análise dos dados da categoria CPC evidencia a importância das atividades que ocorrem no laboratório didático de física e no centro de ciências para a formação do licenciando na articulação entre conteúdo ensino. Enquanto no LDF o ALF-1 construiu uma proposta que envolvia a elaboração de um experimento que foi construído utilizando uma linguagem mais próxima dos alunos para ser atingido um objetivo específico, no centro de ciências, o ALF-2 preocupou-se com o conhecimento prévio desses alunos, fazendo adaptações nos experimentos para que os conteúdos que 
deveriam ser trabalhados (movimento, força e energia) pudessem ser apresentados numa linguagem acessível aos estudantes do EM.

Por fim, este tipo de parceria trouxe para os licenciandos a oportunidade de entrar em contato com professores e alunos do EM, numa perspectiva diferente do contexto da sala de aula tradicional, de forma que novas situações e problemas emergiram deste novo contexto. Diante disto, a oportunidade que os licenciando tiveram de trabalhar no laboratório didático e no centro de ciências, junto as reuniões e discussões que lá ocorrem, lhes permitiu criar e ministrar atividades que lhe exigiram compreensão do conteúdo, o entendimento do seu papel dentro do espaço e no experimento desenvolvido com os alunos, adequação da linguagem para o ensino, preocupação com o conhecimento prévio dos alunos, adaptação de atividades e o envolvimento com professores do EM. Todos esses se configuram, em nossa análise, como processos formativos potencializadores da construção de elementos de CPC, essenciais na formação dos professores.

\section{Referências}

Almeida, P. C. A. D., Davis, C. L. F., Calil, A. M. G. C., \& Vilalva, A. M. (2019). Categoras teóricas de Shulman: revisão integrativa no campo da formação docente. Cadernos de Pesquisa, 49(174), 130-149.

Alvarenga, B., Máximo, A (2000). Curso de Física Volume 1. São Paulo, Ed. Scipione.

Barcelos, N. N. S., \& Villani, A. (2006). Troca entre universidade e escola na formação docente: uma experiência de formação inicial e continuada. Ciênc. educ.(Bauru), 73-97.

Berry, A., L., J., \& Van Driel, J. H. (2008). Revisiting the roots of pedagogical contente knowledge. International Journal of Science Education, 30 (10). 1271-1279.

Bolívar, A. (2005). Conocimiento didáctico del contenido y didácticas específicas. Profesorado. Revista de curriculum y formación del profesorado, 9(2), 1-39.

Bortoletto, A. (2013). Formação Continuada de Professores: A Experiência de uma Temática Sociocientífica na Perspectiva do Agir Comunicativo. (Tese de Doutorado em Educação em Ciências). Universidade Estadual Paulista Julio de Mesquita Filho, Bauru.

Brasil, Conselho Nacional de Educação. (2015). Resolução no ${ }^{\circ}$, de $1^{\circ}$ de Julho de 2015. Define as Diretrizes Curriculares Nacionais para a formação inicial em nivel superior (cursos de licenciatura, cursos de formação pedagógica para graduados e cursos de segunda licenciatura) e para a formação continuada. Diário Oficial da União.

Cochran, K. F., DeRuiter, J. A., \& King, R. A. (1993). Pedagogical contente knowing: $\mathrm{Na}$ integrative model for teacher preparation. Journal of teacher Education, 44(4), 263-272.

Dourado, L. F. (2015). Diretrizes curriculares nacionais para a formação inicial e continuada dos profissionais do magistério da educação básica: concepções e desafios. Educação \& Sociedade, 36(131), 299-324.

Etkina, E. (2010). Pedagogical contente knowledge and preparation of high school physics teachers. Physical Review Special Topics-Physics Education Research, 6(2), 020110. 
Goes L. F. (2014). Conhecimento Pedagógico do Conteúdo: estado da arte no campo da educação e no ensino de química. 155f. Dissertação (Mestrado em Ensino de Ciências), - Instituto de Química, Universidade de São Paulo, São Paulo.

Henze, I., Van Driel, J. H., \& Verloop, N. (2008). Development of experience d science teachers' pedagogical contente knowledge of model sof the solar system and the universe. International Journal of Science Education, 30(10), 1321-1342.

Jing-Jing, H. U. (2014). A critical review of pedagogical contente knowledge'components: Nature, principle and trend. International Journal of Education and Research, 2(4), 411-424.

Lee, E., \& Luft, J. A. (2008). Experienced secondary science teachers' representation of pedagogical content knowledge. International Journal of Science Education, 30(10), 1343-1363.

Magnusson, S., Krajcik, J., \& Borko, H. (1999). Nature, sources, and development of pedagogical contente knowledge for Science teaching. In Examining pedagogical contente knowledge (pp. 95-132). Springer, Dordrecht.

Melo-Niño, L. V. M., Mellado, V., \& Buitrago, A. (2016). Desarrollo del conocimiento didáctico del contenido en el caso de la enseñanza de la carga eléctrica em Bachillerato desde la práctica de aula. Revista eureka sobre enseñanza y divulgación de las ciencias, 459-475.

Melo-Niño, L. V., \& Mellado, V. (2017). Initial characterization of Colombian high school physics teachers' pedagogical contente knowledge on electric fields. Research in Science Education, 47(1), 25-48.

Orquiza de Carvalho, L. M. (2005). A educação de professores como formação cultural: a constituição de um espaço de formação na interface entre a universidade e a escola. Universidade Estadual Paulista "Julio de Mesquita Filho", Faculdade de Engenharia de Ilha Solteira, Ilha Solteira.

Park, S., \& Oliver, J. S. (2008). Revisiting the conceptualisation of pedagogical contente knowledge (CPC): CPC as a conceptual tool tounderst and teachers as professionals. Research in Science Education, 38(3), 261-284.

Pereira, M. S. F. (2019). A prática educativa no cenário atual: novos e velhos problemas. In: Souza, C. E. S. Formação Inicial de Professores: Práticas Pedagógicas, Inclusão Educacional e Diversidade.Paco Editorial, São Paulo.

Shulman, L. S. (1986). Those who understand: Knowledge growth in teaching. Educational researcher, 15(2), 4-14.

Shulman, L. (1987). Knowledge and teaching: Foundation sof the new reform. Harvard educational review, 57(1), 1-23.

Shulman, L. S., \& Hutchings, P. (2004). Teaching as community property: Essaysonhighereducation. Jossey-Bass.

Shulman, L. S. (2015). Conhecimento e ensino: fundamentos para a nova reforma. Cadernos Cenpec| Nova série, 4(2).

Tenreiro-Vieira, C., \& Vieira, R. M. (2016). Educação em ciências e matemática com Orientação CTS Promotora do Pensamento Crítico. CTS: Revista iberoamericana de ciencia, tecnología y sociedad, 11(33), 143-159.

Verdugo-Perona, J. J., Solaz-Portolés, J. J., \& Sanjosé-López, V. (2017). El conocimiento didáctico del contenido en ciencias: estado de la cuestión. Cadernos de pesquisa, 47(164), 586-611. 